\title{
Pluralidade e diálogo inter-Religioso: POSSibilidades E LIMITES DAS ATUAIS ABORDAGENS PLURALISTAS
}

\author{
Marciano Adilio Spica ${ }^{l}$
}

\begin{abstract}
Resumo: A questão que move este trabalho é a seguinte: é possível justificar e fomentar o diálogo inter-religioso, através das abordagens pluralistas atuais? Pretende-se empreender uma análise de duas teorias pluralistas, mostrando suas vantagens e limites, para justificar e fomentar o diálogo inter-religioso. Num primeiro momento, será feita uma breve introdução e contextualização dos problemas filosóficos gerados pela diversidade religiosa. Feito isso, seráo apresentadas e discutidas duas teorias pluralistas atuais. Será focalizada primeiramente a teoria pluralista de John Hick, o qual possui uma proposta de justificação do pluralismo religioso que tem como ponto central a distinção, emprestada de Kant, entre a realidade fenomênica e a realidade numênica ou entre fenômeno e coisa em si. É daí que seu pluralismo pode ser chamado de pluralismo transcendental. Serão abordados e discutidos os principais conceitos, alcances e limites dessa teoria. Após isso, o mesmo se fará com a teoria de Victoria Harrison, conhecida como pluralismo internalista, que parte de uma adaptação do realismo interno de Putnam ao âmbito da diversidade religiosa. Por fim, esboçar-se-á uma avaliaçâo comparativa das duas teorias, analisando-se as possibilidades e limites dessas teorias, no que se refere ao diálogo inter-religioso.
\end{abstract}

Palavras-Chave: Diversidade. Religião. Filosofia. John Hick. Victoria Harrison.

\section{CONSIDERAÇÓES INICIAIS}

As sociedades atuais, principalmente as ocidentais, convivem com uma ampla gama de diversidade de crenças. É possível encontrar, no mesmo espaço público, católicos, evangélicos, muçulmanos, budistas, ateus, agnósticos, umbandistas, e muitos outros. Nesse cenário marcadamente pluralista, é necessário que haja um diálogo inter-religioso e das religióes com os não religiosos, a fim de tornar minimamente possível uma convivência pacífica entre os mesmos. A filosofia, aqui, teria o papel importante de desenvolver reflexóes

\footnotetext{
${ }^{1}$ Professor Associado do Departamento de Filosofia da Universidade Estadual do Centro-Oeste (UNICENTRO), Guarapuava, PR - Brasil. E-mail: marciano.spica@gmail.com

Membro do Programa de Pós-graduação em Filosofia da Universidade Estadual do Oeste do Paraná (UNIOESTE).
}

http://dx.doi.org/10.1590/0101-3173.2018.v41n4.08.p135 
que deem conta dessa necessidade - e é isso que muitos filósofos vêm tentando fazer, nos últimos anos, nos quais artigos e livros sobre os problemas gerados pela diversidade religiosa têm-se multiplicado, levando alguns até a defender uma nova abordagem para a disciplina Filosofia da Religião. ${ }^{2}$ Tal abordagem se focaria mais numa discussão comparativa das diferentes religióes existentes do que nos problemas tradicionalmente tratados por essa disciplina, no ocidente, como o problema da existência de Deus, o problema do Mal, dentre outros.

A vasta produção filosófica a respeito da diversidade de crenças religiosas é, geralmente, dividida em três grandes grupos de abordagem, a saber, exclusivismo, inclusivismo e pluralismo. ${ }^{3}$ Pode-se dizer que o exclusivismo defende, resumidamente, que a verdade e/ou a salvaçấo só pode ser encontrada em uma única religião mundial ou, ao menos, não há nenhum problema lógico e/ou epistemológico em fazer tal afirmação. Essa foi, por exemplo, a posição adotada pela Igreja Católica até o Concílio Vaticano II, através da doutrina extra ecclesiam nulla salus ${ }^{4}$ (fora da igreja, não há salvação), e é a posição de respeitados pensadores, como Karl Barth (1956) e Alvin Plantinga (2000). O inclusivismo, por outro lado, é uma posição que tenta sintetizar as respostas pluralistas e exclusivistas defendendo, resumidamente, que mesmo que exista uma única religião verdadeira e, em consequência, uma doutrina que seja a verdadeira, os que não concordam com essa doutrina podem ser salvos. Sáo defensores dessa posição, por exemplo, Jacques Maritain (1959) e Karl Rahner (2001). Apesar da riqueza argumentativa das teorias que defendem o exclusivismo e o inclusivismo, entendo que não levam a sério a diversidade religiosa e a possibilidade de um diálogo inter-religioso. Diante disso, quero me focar na posição filosófica pluralista, a qual, a meu ver, é uma resposta mais plausível para a diversidade, por não negar a legitimidade dela e tornar mais viável a possibilidade de uma convivência entre as diferentes religióes existentes.

O pluralismo pode ser caracterizado como a posição em face da diversidade que defende que não há problemas lógicos e/ou epistemológicos em

\footnotetext{
${ }^{2}$ Ver, por exemplo, Schelemberg (2008).

${ }^{3}$ Alguns autores trabalham com uma divisão ainda maior, colocando, por exemplo, o relativismo como mais uma posição filosófica a respeito da diversidade (RUNZO, 2010, p. 61-76).

${ }^{4}$ Não estamos com isso afirmando que a Igreja Católica abandonou totalmente a ideia de que a salvação se dá dentro da Igreja, mas afirmando apenas que, a partir do referido Concílio, a Igreja se abre para um possível diálogo inter-religioso, o qual a própria Igreja considera fazer parte "da missão evangelizadora da Igreja, [e que] comporta uma atitude de compreensão e uma relação de recíproco conhecimento e de mútuo enriquecimento, na obediência à verdade e no respeito da liberdade." (RATZINGER, 2000).
} 
se postular crenças diversas sobre um mesmo assunto. Tratarei aqui, especificamente, de duas teorias pluralistas que são antagônicas e refletem, segundo minha compreensão, dois extremos na abordagem pluralista da diversidade, isto é, o pluralismo transcendental de John Hick e o pluralismo internalista de Victoria Harrison. Pretendo fazer uma comparação entre essas duas teorias e, ao final, defender que elas, apesar de terem a vantagem de serem pluralistas, são insuficientes para justificar e fomentar um possível diálogo inter-religioso.

Antes de fazer a apresentação e a análise das teorias pluralistas que pretendo abordar, gostaria de justificar o porquê de sua escolha como objeto de minha análise. A escolha pela teoria de John Hick se justifica pelo fato dela ser, possivelmente, a mais influente das teses pluralistas, sendo citada e tomada como pano de fundo por muitos autores que trabalham a diversidade religiosa e, para um estudo que almeja analisar a importância e a abrangência dessas teses, a teoria de Hick não poderia ficar de fora. Já a tese de Victoria Harrison é uma tese recente e ainda pouco conhecida do grande público em geral, e até mesmo do público filosófico. Mas, a meu ver, tal tese é bastante promissora e se coloca realmente como uma tese opositora forte de Hick, sem perder de vista a possibilidade de uma abordagem pluralista.

\section{Pluralismo transcendental de John Hick}

Hick possui uma proposta de justificação do pluralismo religioso que tem como ponto central a distinção, emprestada de $\mathrm{Kant}^{5}$, entre a realidade fenomênica e a realidade numênica ou entre fenômeno e coisa em si. É daí que seu pluralismo pode ser chamado de pluralismo transcendental. Para Kant, a única coisa passível de conhecimento é a realidade fenomênica; a coisa em si ou realidade numênica é algo que não podemos conhecer ou a que não temos acesso. Hick aplica essa distinção à questão da pluralidade de crenças religiosas, fazendo uma separação entre o real ou transcategorial (equivalente ao numênico) e as várias formas nas quais o real é pensado ou experienciado, nas diversas manifestaçóes religiosas (equivalente ao mundo fenomênico). Essa

5 É preciso esclarecer que Hick não tem uma perspectiva kantiana a respeito da religião, como ele mesmo afirma: "Kant estava discutindo percepção sensível e não aplica a distinção à religião - sua própria filosofia da religião era totalmente diferente e ele presumivelmente não teria aprovado o uso de tal distinção feita pelos pluralistas religiosos do século XX e século XXI. A distinção entre a realidade em si e a mesma realidade como um objeto da consciência humana, com a indispensável contribuição que a atividade humana faz, é o único aspecto de sua filosofia que eu pegarei emprestado, não precisamos (ou necessitamos) da totalidade de seu complexo sistema arquitetônico de formas e categorias." (HICK, 2010, p. 163). 
distinção só é possível porque, para o filósofo em questão, as manifestações religiosas não são meramente projeçóes humanas, mas envolvem uma resposta a uma realidade transcendente. Ou seja, para ele, todas as grandes religióes do mundo possuem a ideia de transcendência e, mais do que isso, "todas as grandes fés mundiais afirmam, em seus modos diferentes, a impossibilidade de descrever a natureza do último." (HICK, 2010, p. 164).

De acordo com Hick (2010), a grande variedade de religiôes que se encontram no mundo se dá pelo fato de essas serem tentativas de descriçóes da realidade última, concebida como o real ou transcategorial. O real é algo a que nenhuma religiâo tem acesso, ou melhor, nenhuma religião pode se dar o luxo de afirmar que tem uma descrição completa dele, já que qualquer tentativa de o descrever, como ele realmente é, sempre falha, devido às formas do nosso pensamento, as quais são limitadoras do conhecimento. Quando se entende isso, compreende-se a legitimidade de todas as descriçóes existentes, pois todas elas não conseguiriam legitimamente dizer o que é o real em si, apenas podem ter descriçóes do real mediadas pelas nossas formas do pensamento.

Como nenhuma religião pode ter acesso ao real em si, Hick defende que nenhum exclusivismo ou inclusivismo fazem sentido. Ambos precisariam de um acesso privilegiado ao real ou de uma descrição do real em si. Entretanto, dada a distinção de viés kantiano entre real em si e o real fenomênico, tal acesso ou descrição é impossível a qualquer ser humano. Ou seja, nenhum ser humano ou sistema de crenças tem acesso pleno ao real. Diante do fato de que nenhuma religiáo pode dizer que tem acesso pleno ao real, ou seja, nenhuma delas tem uma verdade completa e definitiva sobre ele, não se pode também descartar qualquer interpretação dele como falsa, visto que, para isso, seria necessário estar em posse de uma interpretação verdadeira do real. Dessa forma, todas as interpretaçôes são legítimas e o pluralismo estaria justificado e deveria ser respeitado.

Em face da vasta obra de Hick a respeito do tema, alguns pormenores a respeito de sua tese precisam ser levados em conta, se quisermos realmente fazer justiça ao seu trabalho. Sumner Twiss (2000, p. 68-71), em The philosophy of religious pluralism: a critical appraisal of Hick and his critics, faz um excelente resumo das principais peculiaridades da obra de Hick. Para ele, o argumento pluralista de Hick precisa ser observado dentro de quatro fases interconectadas, a saber: a fase das pressuposiçóes filosóficas, os passos metodológicos, um postulado ontológico e as consequências epistemológicas. As 
fases propostas por Twist são, a meu ver, uma excelente maneira de entender a obra de Hick, de modo que eu me aterei a elas, por algum tempo.

Em Problems of religious pluralism, Hick (1985, cap. 2), mostra que sua abordagem da diversidade religiosa pressupóe uma noção de que as diversas religiôes devem ser concebidas como sistemas linguístico-culturais, similarmente à ideia wittgensteiniana de jogos de linguagem. Esses sistemas são estruturados ao redor de práticas soteriológicas, as quais levariam à transformação do crente. Dessa maneira, ele prioriza a prática religiosa, ao invés da teoria ou doutrina, porém, afirma que tais práticas são respostas humanas à realidade divina ou ao real. Uma análise cuidadosa de seus pressupostos filosóficos enseja perceber uma certa junção de teses wittgensteinianas sobre religião, principalmente aquelas ligadas à ideia de que o mais importante da vida religiosa é a prática, com uma tese ontológica, a qual veremos abaixo, bastante antiwittgensteiniana, conforme resume Twiss (2000, p. 68):

Por um lado, sua teoria adere à visão wittgensteiniana de linguagem e crença religiosa, que é usualmente entendida para conceber a realidade divina como internamente relacionada à práticas e para construir o discurso religioso como gramatical antes que referencial. Por outro lado, ele também adere à visão de que a crença e a linguagem religiosa são propriamente entendidas como pressupondo uma realidade divina última independente e ontológica.

Essas duas pressuposições filosóficas aparecem claramente em God has many names, obra na qual Hick (1982, p. 18-19) escreve que as grandes religióes do mundo são compreendidas por ele como "diferentes respostas humanas a uma realidade divina, incluindo diferentes percepçóes que foram formadas em diferentes circunstâncias históricas e culturais”.

Para além dessas pressuposiçôes filosóficas que unem uma tese wittgensteiniana a um realismo ontológico, Hick tem como hipótese metodológica a convicção de que as experiências e pensamentos religiosos medeiam um contato real com uma realidade superior. Essa é uma convicção que, para ele, é razoável e verídica, tanto para sua própria religião quanto para todas as outras grandes religiôes mundiais, ou seja, assim como é verídico que sua religião medeia um contato com a realidade superior, também é verídico que as outras religiôes também medeiam um contato real com uma realidade superior. Isso faz com que ele defenda uma identidade na pluralidade, isto é, todas as grandes religióes mundiais, apesar de sua formação histórico-cultural diferenciada, 
possuem uma identidade comum, a saber, o mesmo objetivo soteriológico - e essa é uma pressuposição metodológica importante, no estudo da diversidade religiosa.

A terceira fase do argumento de Hick envolve um postulado ontológico forte, quer dizer, o postulado de uma realidade noumenal divina, subjacente e unificadora da diversidade do fenômeno religioso humano. Essa realidade é um referente comum a todas as religiōes. Malgrado nenhuma delas tenha acesso completo a essa realidade, sua manifestação aparece de diferentes formas (pessoal ou impessoal), em diversas culturas. Hick deixa muito claro que a realidade noumenal nunca pode ser acessada por completo, ou seja, não sabemos o que ela realmente é:

Nós não podemos atribuir ao real qualquer atributo intrínseco [...], embora as limitaçóes de nossa linguagem obriguem-nos a falar dele no singular em vez de no plural [...]. Nosso sistema de conceitos humanos não pode abranger a ultimidade do real. É somente como humanamente pensado e experienciado que o real se encaixa em nossas categorias humanas. (HICK, 1995 , p. 50).

Essas três fases anteriores têm algumas consequências epistemológicas importantes, para a abordagem pluralista de Hick. As diferenças entre as religiôes se dáo no fato de estas serem respostas alternativas ao mesmo objeto de crença, isto é, o real. $\mathrm{Na}$ verdade, ele não vê uma diferença profunda entre as diferentes religióes, mas uma identidade subjacente à diversidade, a qual poderíamos chamar de uma deficiência comum, ou seja, nenhuma delas consegue acesso ao real como tal; diante disso, todas as reivindicaçóes de verdade absoluta das religiôes caem por terra e, por essa razão, Hick sustenta que tenhamos uma espécie de agnosticismo em relação às reivindicaçóes de verdade das religiôes. Porém, isso não seria uma defesa de um não-cognitivismo religioso, porque, em sua opiniâo, os dados essenciais das religiôes, sua soteriologia, ainda são esquemas verificáveis escatologicamente.

\subsection{Algumas críticas à abordagem de Hick}

Apesar da elegância da teoria de Hick, suas ideias estão sofrendo fortes críticas, e as mais contundentes dizem respeito à separação entre fenômeno e númeno e às consequências daí derivadas. Alvin Plantinga, por exemplo, critica o fato de Hick (1989, p. 239 ss) defender que nenhum termo utilizado pela 
linguagem humana se refere ao real, de forma substantiva. Plantinga (2000a, p. 45) escreve:

Se Hick defende que nenhum de nossos termos aplicam-se literalmente ao real, então não é possível fazer sentido o que ele diz. Aceito que o termo triciclo não se aplica ao real; o real não é um triciclo. Mas, se o real não é triciclo, então, "não é um triciclo" aplica-se literalmente a Ele. Ele não é um triciclo. Ele dificilmente poderia ser nem um triciclo nem um nãotriciclo e nem penso que Hick sugeriria isso.

Com essa crítica, Plantinga sustenta a impossibilidade lógica de uma afirmação como a de que nenhum conceito pode ser realmente atribuído ao real.

Na mesma esteira da crítica de Plantinga, Wainwright (2005, p. 225), por exemplo, assinala que a tese de Hick é baseada em fatos "alegadamente incontroversos" e em uma profissão de fé. E o problema maior está justamente na profissão de fé. Ela diz respeito à afirmação de Hick de que todas as religiôes envolvem uma resposta a uma realidade transcendente e que todas elas parecem ser igualmente válidas. Para Wainwright, Hick necessita dessa profissão de fé, a fim de justificar o fato de as religiôes não serem meramente projeções humanas, ou seja, para não cair na ideia ateísta de que Deus é um produto da mente humana. Mas o problema é que o real é concebido de forma muito diversa, nas distintas religióes, de sorte que dizer que todos os entendimentos são válidos é de difícil aceitação, já que temos deidades boas e más, manifestações deístas e teístas, e parece que, de acordo com Hick, tudo seria válido. Dado que o real é transcategorial, não há base para afirmar que uma resposta ao real é melhor que outra, assim, o mesmo atributo que é válido para Allah não é válido para Brahma, nas religióes experienciadas, contudo, ambos seriam respostas ao real, o que parece ser de difícil aceitação, tanto do ponto de vista lógico quanto do ponto de vista experiencial, porque dificilmente as diversas religióes aceitariam uma tal perspectiva. ${ }^{6}$

\section{O pluralismo interno de Victoria Harrison}

É para tentar superar as críticas sofridas pela tese de Hick, sem deixar de lado uma perspectiva pluralista, que Victoria Harrison desenvolve sua tese

\footnotetext{
${ }^{6}$ Além das críticas apresentadas, existem várias outras como, por exemplo: (D’COSTA, 1996; PLANTINGA, 2000b).
} 
pluralista chamada pela própria autora de pluralismo internalista. Ela define o pluralismo internalista assim:

Uma adaptação, aos domínios religiosos, do realismo internalista - uma teoria primeiramente defendida por Hilary Putnam. Como o realismo interno putniano, o defensor do pluralismo internalista sustenta que seja qual for o objeto que pode ser dito existir, ele é dependente de um esquema conceitual e seja qual for o significado de um objeto existir, ele é igualmente dependente de um esquema conceitual. (HARRISON, 2008, p. 98).

Basicamente, o que Harrison pretende é adaptar as teses de Putnam, as quais podem ser resumidas na metáfora criada pelo filósofo - "mente e mundo criam mente e mundo" - e que surge como uma crítica ao realismo metafísico, o qual, conforme Putnam (1992, p. 49), possui três teses fundamentais:

$\mathrm{O}$ mundo consiste de alguma totalidade de objetos independentes da mente. Há exatamente uma verdadeira e completa descrição de "como o mundo é". A verdade envolve algum tipo de correspondência entre palavras ou signos do pensamento e coisas ou classes de coisas externas.

Como alternativa a essa visão metafísica, Putnam elabora uma teoria que fugiria de uma dicotomia verdade/razão subjetiva e objetiva, negando, em primeiro lugar, que exista uma necessária correlação entre declaração e realidade e alguma classe de realidade independente da mente. Para ele, os objetos que supostamente existem são dependentes de um esquema conceitual e, mais do que isso, a própria ideia "algo existe" é dependente do esquema conceitual adotado, sendo que a ideia de verdade é algum tipo de "aceitabilidade racional (idealizada)" que pressupóe uma coerência de nossas crenças umas com as outras e dessas com as experiências representadas no nosso sistema de crenças.

Segundo Harrison (2006a), se aplicarmos as ideias do realismo internalista de Putnam ao entendimento da diversidade religiosa, podemos desenvolver uma tese pluralista internalista, a qual teria como centralidade a ideia de que as realidades e declaraçóes religiosas podem somente ser entendidas e discutidas corretamente dentro de um esquema conceitual particular, não fazendo sentido falar de um "real" que exista fora de um esquema conceitual. Conforme a filósofa, essa seria uma verdadeira revolução no modo como concebemos a diversidade, já que não haveria um centro ao redor do qual as religióes particulares giram e que esteja fora de seu esquema conceitual. Nesse sentido, uma defesa do pluralismo de crenças, para ser consistente, deveria 
reconhecer que uma discussão significativa das pretensas realidades e verdades religiosas só é possível se forem compreendidas dentro de seus respectivos esquemas conceituais ou "instâncias de fé":

Se dois diferentes conjuntos de afirmaçóes religiosas contêm verdades, elas permaneceriam verdades sem qualquer forma de correspondência a alguma realidade fora de todos os sistemas de crenças religiosos ou seculares. Ainda, do ponto de vista do realismo internalista, não há realidade "existindo" fora de nossos esquemas conceituais. (HARRISON, 2006a, p. 292).

Em resumo, o que o pluralismo interno propóe é que cada afirmação religiosa tem sentido dentro de sua instância de fé. Os esquemas conceituais que formam a realidade e as verdades determinam o que conta como verdadeiro e o que não conta como verdadeiro, o que conta como real e o que não conta como real. Dessa forma, o problema da disputa entre as diferentes religióes seria dissolvido, já que não pode haver uma "legítima disputa entre diferentes sistemas de crenças sobre a objetividade de suas respectivas reivindicaçóes, a menos que eles entrem genuinamente no sistema de crenças um do outro" (HARRISON, 2006a, p. 293), e teríamos uma radical teoria do pluralismo, na qual a pluralidade seria realmente levada a sério.

Para Harrison, sua teoria tem enormes vantagens em relação àquela de Hick. Em Internal realism and the problem of religious diversity (2006a, p. 288) ela defende, usando uma expressão de Imre Lakatos, que, apesar das inúmeras modificaçóes ad hoc que Hick tem feito em sua teoria, suas ideias para explicar a diversidade religiosa estão em degenerescência e precisam sempre de novas hipóteses auxiliares para dar conta dos problemas gerados pela diversidade religiosa. Por outro lado, isso não aconteceria com o pluralismo internalista, porque este leva realmente a sério o problema da diversidade. É desse modo que Harrison acredita que sua teoria tem, no mínimo, sete vantagens em relação à tese de Hick (HARRISON, 2006a, p. 295-298).

A primeira vantagem se dá no quesito verdade. Ou seja, a tese de Harrison permitiria aos religiosos usarem o termo verdade, enquanto a tese de Hick parece não permitir isso, pelo fato de que este adota a separaçáo entre fenômeno e númeno, afirmando que o Deus no qual um religioso acredita não é o Deus real, apenas uma interpretaçáo (que pode estar totalmente errada) do real. Isso seria, na perspectiva de Harrison, uma forma de descrever a religião que não se encaixa em como os próprios crentes entendem suas próprias crenças. É difícil conceber que algum crente aceitaria a ideia de que o Deus em 
que eles acreditam é apenas uma versão limitada ou totalmente errada do Deus verdadeiro. Uma perspectiva internalista, por sua vez, preconiza que existe verdade objetiva dentro de cada instância de fé, de maneira que os crentes não precisariam reformular suas crenças. O pluralismo internalista deixaria as diferentes instâncias de fé como elas realmente estão, isto é, com a possibilidade de que as crenças sejam verdadeiras ${ }^{7}$, enquanto a tese de Hick faria com que todos os religiosos tivessem que revisar suas crenças.

Nesse mesmo sentido, enquanto a distinção entre fenômeno e númeno de Hick parece impossibilitar uma ideia de revelação - pois, para que isso acontecesse, Deus teria de se dar ao crente, o que parece impossível, dadas as limitaçóes humanas propostas por Hick -, Harrison sustenta que a ideia de revelaçáo é possível dentro de cada instância de fé, apesar de não ser possível uma revelação transcendente, ou seja, além de toda e qualquer instância de fé. Assim, a teoria de Harrison teria uma explicação melhor das religiōes ditas reveladas.

Um terceiro problema que, segundo Harrison, sua teoria supera é que as teses de Hick parecem levar a uma compreensão de que as diferenças entre religiōes são meramente superficiais e sem grande importância, porque são interpretações as quais não podem ser consideradas melhores, o que diminui a importância dada por um crente a suas próprias crenças. Já o pluralismo internalista evitaria esse problema, ao reconhecer que algumas declaraçóes podem ser verdadeiras dentro de uma instância de fé e falsas, dentro de outra, preservando o fato de que podem haver diferenças genuínas entre diferentes religiốes.

A quarta vantagem do internalismo é que ele não crê que a maioria das declaraçôes religiosas sejam "mitológicas (ou "praticamente verdadeiras"), como Hick parece defender. Para o internalismo, "a menos que as religióes possam fazer declaraçóes proposicionais, elas pareceriam desprovidas da habilidade de transmitir informaçôes genuínas.” (HARRISON, 2006a, p. 297). E é claro que há transferência de informação e proposiçóes dentro das diferentes religióes, mesmo que sua verdade seja restrita ao interior de cada sistema. Nes-

\footnotetext{
${ }^{7}$ Aqui é necessário esclarecer que Harrison năo acredita que tudo o que é dito dentro de um esquema conceitual seja verdadeiro, o que distinguiria sua teoria, por exemplo, de um idealismo subjetivista que retrataria as coisas como simplesmente dependentes de um esquema conceitual. "De acordo com o realismo internalista, um esquema conceitual determina o que se identificará como objeto. Mas isto não garante que tais objetos realmente serão encontrados.” (HARRISON, 2008, p. 102).
} 
sa perspectiva, o internalismo náo transforma todas as religióes em meras narrativas mitológicas.

Além disso, enquanto a teoria de Hick falha em providenciar um relato convincente de religióes que não reconhecem uma figura divina, fazendo com que religióes como o budismo, por exemplo, sempre apareçam como anômalas, o pluralismo internalista respeitaria todas as perspectivas religiosas, pois não está comprometido com a ideia de um real que transcende todas as religióes e, por isso, não precisaria fazer modificaçóes ad hoc para explicar uma religião onde não há a figura de um Deus.

Uma suposta sexta vantagem da teoria de Harrison sobre a de Hick é que, enquanto este insiste que todas as religióes encorajam as pessoas a se moverem rumo a um mesmo objetivo - e que conceitos tais como "nirvana", "moksha" "salvação" são todos equivalentes -, o que parece implausível, o pluralismo internalista defende que o significado de cada conceito religioso só é acessível no interior de cada sistema. Essa ideia respeita as diferenças conceituais entre as diferentes religióes e não permite reduzir as diversas buscas das diferentes religióes a uma única busca.

Por último, Harrison acusa a teoria de Hick de não dar uma explicação plausível para o ateísmo, o qual acaba sendo caracterizado como uma resposta moral ao real, enquanto sua tese possibilita admitir que o ateísmo seja mais um sistema de crenças, já que o pluralismo internalista leva a sério todos os sistemas, sejam eles seculares, sejam religiosos.

A tese de Harrison, nessa linha, pode ser caracterizada como um pluralismo radical, por não aceitar que haja algo comum a todas as instâncias de fé. Mas tal radicalidade poderia levar a uma compreensão do pluralismo internalista como relativista ou subjetivista. Harrison afirma, porém, que tais rótulos, se empregados contra sua teoria, não fazem sentido, porque, no caso do relativismo, há uma negação da verdade objetiva, enquanto, no pluralismo internalista, a verdade pode ser avaliada e tem objetividade dentro de cada esquema conceitual. No fundo, o pluralista internalista não rejeita a verdade, apenas a coloca dentro de cada esquema conceitual. Uma acusação de subjetivismo também não seria adequada, uma vez que este toma como "verdade" aquilo que o crente deseja que seja a verdade, enquanto o pluralista acredita que a verdade é objetiva dentro de um esquema conceitual e está além de desejos e preferências pessoais. 
Além dessas possíveis críticas, o pluralismo internalista precisa dar conta da crítica à sua teoria-base, a saber, a teoria de Putnam. Alston, por exemplo, faz fortes críticas ao realismo de Putnam, em seu texto $A$ sensible metaphysical realism (2001), afirmando que o mesmo é internamente incoerente, porque sua defesa de esquemas conceituais cai em um vício de regresso ao infinito, devido à defesa de que os objetos são dependentes de esquemas conceituais. Basicamente, o que Alston assevera é que, se for feita uma identificação de uma variedade de esquemas conceituais diferentes - nos quais "objetos físicos e fatos tem um certo caráter relativo a um ou outro esquema. Relativo a um dos esquemas alternativos, aqueles objetos e fatos têm uma detalhada constituição, enquanto relativo a outro, eles têm diferentes constituições" (ALSTON, 2001, p. 32) -, restaria a pergunta sobre o que são os esquemas conceituais eles mesmos, quer dizer, que tipo de objetos eles seriam? E seria preciso um segundo nível de esquema conceitual para dar conta de explicar o que são os esquemas conceituais, e um terceiro nível, para explicar a explicação do segundo e, assim, teríamos um regresso ad infinitum. ${ }^{8}$

\section{Pluralismo e diálogo inter-Religioso}

Até aqui, eu me ative em apresentar duas teorias pluralistas antagônicas. Agora, pretendo fazer uma comparação avaliativa dessas teorias, mostrando as possibilidades das mesmas em explicar a diversidade religiosa e a possibilidade do diálogo inter-religioso. A meu ver, a teoria de Harrison realmente tem algumas vantagens em relação à teoria de Hick, e a principal é sua abrangência. Ou seja, enquanto a teoria de Hick comporta uma explicação razoável das diferentes religióes teístas, sua explicaçáo das religióes deístas realmente soa como se estas fossem anômalas ao conceito religião. Mesmo que ele afirme que o real pode ser compreendido numa perspectiva tanto pessoal (teísta) quanto impessoal (deísta), algumas religióes teriam problemas em ser enquadradas nessa definição, como é o caso do budismo. Já a teoria de Harrison parece dar conta de explicar tanto a existência de religióes teístas quanto deístas e o budismo.

A falta de abrangência da teoria de Hick se dá pelo que vou chamar aqui de tentativa de generalizaçáo, usando uma ideia trabalhada por Witt-

\footnotetext{
${ }^{8}$ Uma tentativa de resposta a essa crítica é apresentada por Harrison (2006a, p. 299), em Internal realism and the problem of religious diversity. Não temos espaço, neste texto, de nos ater aos detalhes dessa resposta.
} 
genstein. ${ }^{9}$ Hick generaliza, a todas as religiōes existentes, uma ideia que se faz presente no seu próprio sistema de crença. Ao fazer isso, impóe sua maneira de ver a religiáo a todos os modos existentes, esquecendo-se de que diferentes religióes podem ter diferentes imagens de mundo. Nesse sentido, apesar de partir de uma perspectiva interessante, que é a de que podemos entender as diversas religióes como diferentes jogos de linguagem, sua tese ontológica forte o faz cair num erro que o formulador da ideia de jogos de linguagem, Wittgenstein, queria evitar, a saber, a busca por uma essência ou a defesa de algo comum a todos os jogos de linguagem. A despeito de a ideia de essência ser atrativa, geralmente ela é excludente. Isto é, apenas aquilo que se enquadra dentro da minha perspectiva é o que é certo, outras coisas não, o que, conforme minha perspectiva, é sempre um empecilho para o diálogo.

Um defensor da tese de Hick poderia se defender dessa acusação, dizendo que não há como a ideia do real ser excludente, pois todas as religióes são projeçôes dela, não há nenhuma religião que não seja a projeção de nossas percepçóes limitadas do real. Isso as une, náo as separa. Isso seria a ponte que permitiria o diálogo. A primeira resposta para refutar esse argumento é a de que a tese de Hick exclui os ateus de um possível diálogo pluralista, pois esses parecem ser "deficientes" de percepçóes limitadas do real. Além do problema do ateu, há igualmente a questão de que se nenhuma religiáo é detentora da verdade e, se nenhuma delas pode se arrogar o direito de ter uma descrição mais ou menos verdadeira do real - segundo a tese de Hick, não podemos nem mesmo falar em gradaçóes de confiabilidade das crenças religiosas -, qual seria o conteúdo de um possível diálogo inter-religioso? Provavelmente, seria um diálogo sem frutos. Ou seja, cada um sairia da discussáo com as mesmas crenças com as quais entrou. Na verdade, temos uma tese onde tudo é válido, porque nada é verdadeiro. Num cenário como esse, fica difícil entender qual seria a função de uma possível troca de conhecimentos e experiências. Ora, a tese de Hick, ao contrário do que aparenta, não parece ser uma perspectiva interessante para promover um diálogo inter-religioso autêntico e frutífero.

Por outro lado, Harrison tem uma perspectiva pragmática da definição de religiáo. ${ }^{10}$ Ela argumenta que, pragmaticamente, deveríamos aceitar que as diferentes religióes têm, no máximo, semelhanças de família, aos moldes do

${ }^{9} \mathrm{O}$ desejo por generalização se constitui na atitude filosófica de desprezo pelo particular. Esse desprezo acaba por gerar uma busca de algo comum a toda linguagem. Entre o cantar, o descrever, o rezar, o ler, o discutir, entre outras, deveria haver algo que passasse por todas essas atividades linguísticas. Wittgenstein é um forte crítico desse desejo (WITTGENSTEIN, 1992).

${ }^{10}$ Ver Harrison (2006b). 
que Wittgenstein utilizou nas Investigaçôes filosóficas. Embora essa definição tenha problemas, ao não conseguir fazer uma separação nítida entre religião e algumas manifestaçóes humanas que poderiam, usando a ideia de semelhanças de família, ser chamadas de religiosas, como o nazismo e o marxismo, ela tem a vantagem de não impor às diferentes religióes uma perspectiva particular. Nesse sentido, como mostrei acima, a tese de Harrison realmente deixa as religiôes como elas estão, permitindo a elas viverem suas crenças e acreditarem em verdades objetivas internas a seus sistemas de crenças.

Porém, apesar de ser mais abrangente e ter a vantagem de ser uma explicação mais realista da diversidade religiosa, já que não impõe a elas uma essência ou perspectiva única, não forçando as mesmas a se adequarem a uma visão que as transcende, a tese de Harrisson, assim como a de Hick, parece ter a dificuldade de justificar ou promover o diálogo inter-religioso.

A despeito de Harrison afirmar a possibilidade de diferenças genuínas entre as distintas religiōes, o que, a meu ver, é um grande passo em relação às teses de Hick, essas diferenças não poderiam ser acessadas sem que ocorresse uma espécie de conversão ao sistema de crença alternativo ou através do acesso a um ponto de vista neutro. No primeiro caso, Harrison deixa muito claro que, numa discussão entre dois sujeitos pertencentes a dois sistemas de crenças diversos, ambos podem estar certos, porque a diferença entre eles pode ser uma diferença totalmente dependente de um esquema conceitual (HARRISON, 2008, p. 103). Se for assim, a pergunta que fica é: um diálogo entre os dois seria um diálogo entre dois surdos? Parece que sim, pois nenhum estaria realmente ouvindo o que o outro está a dizer. Cada um está a falar em seu mundo e para seu mundo.

Harrison poderia responder a essa acusação, destacando que, da mesma forma que ela deixa claro que uma diferença é uma diferença completamente dependente de esquemas conceituais, ela enfatiza também que é possível aprender a empregar um novo esquema conceitual. Essa possibilidade de aprender a usar um novo esquema conceitual é, inclusive, ilustrada com vários exemplos (HARRISON, 2008, p. 103). Nesse sentido, uma discussão entre dois sujeitos de esquemas conceituais diferentes não seria um diálogo entre dois surdos, pois sua teoria abre a possibilidade para a conversão religiosa, a qual seria impossível, se um sujeito de um esquema conceitual $A$ não ouvisse um sujeito de um esquema conceitual $B$. Para fins de argumentação, vamos concordar com Harrison de que há um diálogo. Mas, mesmo se isso for verdadeiro, a pergunta que fica é: o único diálogo possível é aquele que leva à 
conversão? Ou seja, só é possível entender crenças de esquemas conceituais diferentes, se houver conversão?

Uma saída para essa crítica seria a adoção de uma perspectiva ficcionalista consoante ao diálogo inter-religioso, perspectiva que Harrison parece estar adotando, em seus últimos trabalhos. A ideia central da tese ficcionalista é que "declaraçôes feitas no interior de uma área de discurso não podem ser vistas como literalmente verdadeiras ou falsas, mas são consideradas como contribuindo para uma ficção." (HARRISON, 2010, p. 50). Nesse sentido, quando se comparam diferentes sistemas de crença, devemos, ao menos para fins de argumentação, adotar a ideia de que todas as alegações feitas em um sistema de crenças estão "contribuindo para uma ficção", incluindo as reivindicações feitas em nosso próprio sistema. É importante perceber que o ficcionalismo não entende que todas ou uma determinada crença é falsa, na verdade, ele não precisa ter esse compromisso forte. Para Harrison, o ficcionalismo é uma atitude de indiferença ontológica frente a objetos de discurso religioso, ou seja, ele não entra na questão da verdade ou falsidade (HARRISON, 2010, p. 52).

O ficcionalismo, dessa forma, poderia ser adotado como uma instância de segunda ordem, um metanível, capaz de dar sentido a diferentes reivindicaçóes de distintos sistemas de crença, que seriam as instâncias de primeira ordem. Assim, para fins de argumentação filosófica sobre a pluralidade de crenças religiosas, não precisaríamos defender a verdade ou falsidade de uma determinada crença, mas adotar todas as crenças de todos os sistemas como ficcionais. Segundo a autora, a adoção do ficcionalismo como uma metodologia de debate filosófico sobre a pluralidade, apesar de ter alguns problemas (HARRISON, 2010, p. 56), seria suficiente para dar conta de explicar e fomentar o diálogo inter-religioso.

Penso que um diálogo inter-religioso não necessita necessariamente ${ }^{11}$ ser um diálogo de conversão, nem mesmo assumir a necessidade de um metanível ficcional. Numa sociedade plural, na qual se assume a existência de diferentes sistemas de crenças como sistemas legítimos, as discussôes não deveriam ou não se dariam para provar que um sistema de crenças como um todo está totalmente errado, mas se poderia discutir que uma determinada crença está equivocada e, por exemplo, dificulta a convivência pacífica entre os diferentes

\footnotetext{
${ }^{11}$ Quando digo que não necessariamente haja um diálogo buscando a conversão, faço isso justamente para não descartar a possibilidade da conversáo. É possível que um sujeito descarte um determinado sistema, para aderir a outro. O que quero enfatizar é o fato de que, muitas vezes, um sujeito de um sistema $A$ apenas quer compreender ou discutir uma determinada crença de um sistema $B$.
} 
sistemas. Obviamente, essa crença singular tem seu sentido dentro de uma pluralidade de crenças com as quais ela está interligada, dentro desse sistema, todavia, a meu ver, isso não impossibilita que o sujeito de um sistema $A$ possa compreender isso, quando está em jogo uma crença do sistema $B$, e não vejo a necessidade de se tomar as crenças como ficcionais.

$\mathrm{Na}$ questão específica do ficcionalismo, entendo que ele tem um problema difícil de resolver e que pesa contra sua aceitação, como forma coerente de explicar a pluralidade. O problema do ficcionalismo reside no fato de que ele assume que, por uma questão de argumento, é possível suspender todas as nossas crenças, para se ter acesso a um ponto de vista neutro. É difícil admitir que um crente religioso aceitaria, por exemplo, tratar suas crenças como ficcionais. Isso exigiria dele a renúncia, nem que por tempo determinado, de sua fé. Mesmo enquanto metodologia filosófica, o ficcionalismo é questionável, pois faria do filósofo um ser capaz de suspender todas as suas crenças e tomar uma posição a partir de um ponto de vista neutro. É difícil imaginar que isso seja possível, e a própria Harrison concorda, ao ressaltar: "Um filósofo ficcionalista da religião poderia muito bem simplesmente decidir julgar outras tradições religiosas a partir da perspectiva oferecida por sua própria ficção" (HARRISON, 2010, p. 57), embora defenda que essa não seria uma atitude intelectualmente correta. Contudo, a principal questão aqui é se realmente é possível ao filósofo se desvencilhar de todas as suas crenças, a fim de avaliar outras crenças. Isso é exigir um ponto de vista neutro ou um metassistema, o que, segundo penso, parece praticamente impossível e não é necessário para defendermos o diálogo inter-religioso. É impossível, porque teríamos de suspender todas as nossas crenças e, como bem coloca Wittgenstein, em On certainty, estamos sempre envoltos em crenças, não podendo nos livrar por completo delas. ${ }^{12}$ Por outro lado, tal ponto de vista neutro não é necessário, como bem assinala Schönbaumsfeld (2007, p. 194):

Posso criticar outras práticas, incluindo práticas religiosas, mas não por referência ao "ajuste" ou falha em "ajustar-se" às formas de vida tomadas "como um todo". Pois não há tal coisa, nem poderia haver tal coisa, como uma forma de vida em geral consistindo em todas as nossas diversas práticas tomadas em conjunto e fornecendo-nos um "conjunto neutro de critérios" contra o qual as práticas individuais podem ser medidas.

\footnotetext{
${ }^{12}$ Veja-se, dentre outros, o $\$ 94$ de On certainty. Para Wittgenstein, é impossível ao crente uma posição neutra, uma perspectiva para além das próprias crenças. Veja-se também Davidson (1991, p. 198ss).
} 
Entendo que, na vida prática, na linguagem ordinária e, por que não dizer, na religião ordinária, há trocas de conhecimentos e práticas. Os diferentes sistemas de crenças não estão completamente desligados e isolados uns dos outros, não há um gap intransponível entre eles. Na verdade, não teríamos nem mesmo como saber ou visualizar esse possível gap, pois não estamos numa posição privilegiada que nos permita perceber se realmente existem conceitos e crenças radicalmente diferentes das nossas. ${ }^{13}$

\section{ObSERVAÇÓES FINAIS}

Este trabalho comparou duas teses pluralistas atuais que buscam justificar a diversidade religiosa, a fim de avaliar suas possibilidades de justificar e fomentar o diálogo inter-religioso. A conclusão é de que, apesar de as teses avaliadas serem bastante plausíveis, elas falham em dar conta do diálogo inter-religioso. Enquanto a tese de Hick parece tomar todas as religióes como diferentes partes de um único sistema (o grande sistema religioso) que teria as manifestaçóes do real como a característica comum a todos eles, Harrison radicaliza o pluralismo, a ponto de tornar praticamente impossível que um encontre outro, sem que seja necessário o abandono das crenças atuais. Nesse sentido, a despeito de as propostas pluralistas terem feito grande avanço na justificação da pluralidade religiosa e na plausibilidade de se adotar uma perspectiva pluralista de crenças, cabe a elas ainda encontrar uma melhor resposta à possibilidade de diálogo inter-religioso. Talvez, a proposta ficcionalista apresentada por Harrison seja um ponto de partida interessante para isso, embora, como mostramos, tenha dificuldades de se sustentar.

O grande desafio talvez seja o de elaborar uma tese pluralista que, ao mesmo tempo, respeite a diversidade e permita o diálogo, sem a imposição de uma perspectiva sobre a outra. Um ponto de acesso poderia ser o entendimento de diferentes sistemas de crenças, nem como sistemas completamente fechados, nem como diferentes sistemas que possuem uma essência comum, mas como sistemas independentes, os quais que possuem certas semelhanças entre uns e outros e, portanto, podem discutir questóes pontuais. Porém, por enquanto, a busca por uma explicação plausível a respeito das possibilidades do diálogo inter-religioso ainda se constitui num desafio importante para as abordagens pluralistas.

${ }^{13}$ Uma abordagem mais aprofundada dessa ideia está em (SPICA, 2018). 
Agradecimento: Este trabalho foi possível graças ao apoio de Bolsa da CAPES, Processo no BEX 0641/15-4. Sou grato também a Victoria Harrison, pela atenção, sugestôes e conversas que ajudaram na elaboração deste e de outros textos, durante minha estada na University of Glasgow.

SPICA, M. A. Plurality and inter-religious dialogue: possibilities and limits of contemporary pluralist approaches. Trans/form/ação, Marília, v. 41, n. 4, p. 135-154, Out./Dez., 2018.

\begin{abstract}
AвSTRACT: Is it possible to justify and promote inter-religious dialogue through current pluralistic approaches? This paper analyses two pluralist theories, showing their advantages and limits in justifying and promoting interreligious dialogue. First I make a brief introduction and contextualization of the philosophical problems generated by religious diversity. Next I present and discuss two current pluralistic theories. The first is the pluralistic theory of John Hick, which in justifying religious pluralism has as its central point the distinction, borrowed from Kant, between phenomenal and noumenal reality; Hick's theory can be called transcendental pluralism. The second is Victoria Harrison's theory, known as internalist pluralism. This theory is an adaptation of Putnam's internal realism to the problems of religious diversity. Finally, I make a comparative evaluation of the two theories, analyzing their possibilities and limitations with regard to interreligious dialogue.
\end{abstract}

KeYwords: Diversity. Religion. Philosophy. John Hick. Victoria Harrison.

\title{
REFERÊNCIAS
}

ALSTON, W. P. A sensible metaphysical realism. Milwaukee: Marquette University Press, 2001.

BARTH, K. Church dogmatics. Edinburgh: T \& T Clark, 1956. V. 1.

DAVIDSON, D. Inquiries into truth and interpretation. New York: Oxford University Press, 1991.

D'COSTA, G. The impossibility of a pluralist view of religious. Religious Studies, v. 32, n. 2, p. 223-232, 1996.

HARRISON, V. S. Internal realism and the problem of religious diversity. Philosophia, v. 34, n. 3, p. 287-301, 2006a.

. The pragmatics of defining religion in a multi-cultural world. International Journal for Philosophy of Religion, v. 59, n. 3, p. 133-152, 2006b. 
. Internal realism, religious pluralism and ontology. Philosophia, v. 36, n. 1, p. 97-110, 2008.

. Philosophy of religion, fictionalism, and religious diversity. International Journal of Philosophy of Religion, v. 68, n. 1/3, p. 43-58, 2010.

An internal pluralist solution to the problem of religious and ethical diversity.

Sophia, v. 51, n. 1, p. 71-86, 2012.

Seeing the Dao: conceptual metaphors and the philosophy of religion. Religious Studies, v. 51, n. 3, p. 307-322, 2015.

HICK, J. God has many names. Philadelphia: The Westminster Press, 1982.

. Problems of religious pluralism. New York: St. Martin's, 1985.

. An interpretation of religion: humanity's varied response to the transcendent. London: Palgrave Macmillan, 1989.

. The rainbow of faiths: critical dialogues on religious pluralism. London: SCM Press, 1995.

The new Frontier of religion and science: religious experience, neuroscience and the transcendent. London: Palgrave Macmillan, 2010.

MARITAIN, J. The degrees of knowledge. Notre Dame: Notre Dame Press, 1959.

PLANTINGA, A. Warranted christian belief. Oxford: Oxford University Press, 2000a.

A defense of religious exclusivism. In: QUINN, P. L.; MEEKER, K. (Ed.). The philosophical challenge of religious diversity. New York: Oxford University Press: 2000b. p. 172-192.

PUTNAM, H. Reason, truth and history. Cambridge: Cambridge University Press, 1992.

RAHNER, K. Christians and the non-christian religions. In.: HICK, J.;

HEBBLETHWAITE, B. (Ed.). Christianity and other religions. Oxford: One World, 2001. p. 19-38.

RATZINGER, J. Declaração Dominus Iesus: sobre a unicidade e a universalidade salvífica de Jesus Cristo e da Igreja. Roma: Congregaçáo para a Doutrina da Fé, 2000. Disponível em: <http:/www.vatican.va/roman_curia/congregations/cfaith/documents/rc_con_ cfaith_doc_20000806_dominus-iesus_po.html>. Acesso em: 15 mar. 2018.

RUNZO, J. Pluralism and relativism. In: MEISTER, C. (Ed.). Oxford handbook of religious diversity. Oxford: Oxford University Press. 2010. p. 61-76.

SCHELEMBERG, J. L. Imagining the future: how scepticism can renew philosophy of religion. In: CHEETHAM, D.; KING, R. (Ed.). Contemporary practice and method in the philosophy of religion: new essays. London: Continuum, 2008. p. 15-31.

SCHÖNBAUMSFELD, G. A confusion of the spheres: Kierkegaard and Wittgenstein on philosophy and religion. Oxford: Oxford University Press, 2017. 
SPICA, M. A. Language, belief and plurality: a contribution to understanding religious diversity. International Journal for Philosophy of Religion. v. 83, n. 2, p. 169-181, 2018.

TWISS, S. B. The philosophy of religious pluralism: a critical appraisal of Hick and his critics. In: QUINN, P. L.; MEEKER, K. (Ed.). The philosophical challenge of religious diversity. New York: Oxford University Press, 2000. p. 67-98.

WAINWRIGHT, W. Competing religious claims. In: MANN, W. (Ed.). The Blackwell Guide to the Philosophy of Religion. Oxford: Blackwell, 2005. p. 220-240.

WITTGENSTEIN, L. On certainty. New York: Harper \& Row, 1972.

. O livro azul. Lisboa: Ediçôes 70, 1992.

Recebido: 13/09/2016

Aceito: 07/03/2018 